\title{
OPTIMASI PENJADWALAN PROYEK PEMBANGUNAN JALAN TOL BECAKAYU SEKSI 1BC DENGAN MENGGUNAKAN METODE CPM DAN PERT
}

\section{OPTIMIZING THE SCHEDULE OF THE BECAKAYU SECTION 1BC TOLL ROAD CONSTRUCTION PROJECT USING THE CPM AND PERT METHODS}

\author{
Ali Murdani Lubis ${ }^{1}$, Endang Suhendar ${ }^{2}$, Puji Suharmanto ${ }^{3}$ \\ ${ }^{1}$ Program Studi Teknik Industri, Fakultas Teknik dan Ilmu Komputer, Universitas Indraprasta PGRI, \\ Jl. Nangka Raya No. 58 C, Jakarta Selatan, DKI Jakarta, Indonesia 12530, email: alimurdanilbs@ gmail.com \\ ${ }^{2}$ Program Studi Teknik Industri, Fakultas Teknik dan Ilmu Komputer, Universitas Indraprasta PGRI, \\ Jl. Nangka Raya No. 58 C, Jakarta Selatan, DKI Jakarta, Indonesia 12530, email: endangunindra@ gmail.com \\ ${ }^{3}$ Program Studi Teknik Industri, Fakultas Teknik dan Ilmu Komputer, Universitas Indraprasta PGRI, \\ J1. Nangka Raya No. 58 C, Jakarta Selatan, DKI Jakarta, Indonesia 12530, email: \\ puji.suharmanto@alumni.ui.ac.id
}

\begin{abstract}
ABSTRAK
Perencanaan pembangunan proyek tentunya memerlukan analisis yang tepat dan sesuai dengan kebutuhan yang diinginkan. Kegiatan ini sangat dibutuhkan karena untuk mengukur berapa biaya yang akan dikeluarkan dan berapa kemampuan biaya untuk membangun proyek tersebut. Pembangunan jalan di Indonesia saat ini sedang berkembang pesat apalagi pada era sekarang ini. Keberhasilan ataupun kegagalan dari pelaksanaan proyek pembangunan jalan sering kali disebabkan kurang terencananya kegiatan proyek serta pengendalian yang kurang efektif sehingga kegiatan proyek tidak efisien. Pengoptimalan waktu pembangunan bertujuan untuk pencegahan keterlambatan proyek dan meminimalisasi biaya serta percepatan kegiatan proyek pembangunan. Pada proyek pembangunan jalan Tol Becakayu Seksi 1BC dengan menggunakan metode CPM terdapat jalur kritis dimana kegiatan pekerjaan tersebut adalah Pekerjaan pembebasan lahan, Pekerjaan pembangunan direksi kit dan gudang, Pekerjaan pondasi, Pekerjaan kolom, Pekerjaan stressing girder, Pekerjaan slab, Pekerjaan pelapisan aspal, Pekerjaan lain-lain dan Pekerjaan finishing. Perusahaan mendapatkan peluang sebesar $79.67 \%$ untuk menyelesaikan proyek pembangunan jalan Tol Becakayu Seksi 1BC setelah melakukan pengolahan data dengan menggunakan metode PERT (Program Evaluation Review Technique).
\end{abstract}

Kata kunci: Manajemen Proyek, Optimasi Penjadwalan, CPM, PERT

\begin{abstract}
Project development planning certainly requires proper analysis and in accordance with the desired needs. This activity is very necessary because it measures how much it will cost and how much it costs to build the project. Road construction in Indonesia is currently growing rapidly, especially in the current era. The success or failure of the implementation of road construction projects is often due to the lack of planned project activities and ineffective control so that project activities are not efficient. Optimization of development time aims to prevent project delays and minimize costs and accelerate development project activities. In the Becakayu Section IBC toll road construction project using the CPM method there is a critical path where the work activities are Land Acquisition Work, Construction Work for Kit and Warehouse Directors, Foundation Work, Column Work, Stressing Girder Work, Slab Work, Asphalt Coating Work, Other Works -Other and Finishing Works. The company has a 79.67\% opportunity to complete the Becakayu Section 1 BC Toll Road construction project after processing data using the PERT (Program Evaluation Review Technique) method.
\end{abstract}




\section{Pendahuluan}

Pembangunan jalan di Indonesia saat ini sedang berkembang pesat apalagi pada era sekarang ini tidak hanya jalan perkotaan tetapi di daerah pedesaan juga banyak ditemui proyek pembangunan jalan. Jalan merupakan kebutuhan utama bagi masyarakat disuatu tempat agar dapat meningkatkan pembangunan diberbagai bidang yang meliputi bidang ekonomi, pendidikan, kesehatan, sosial dan lain sebagainya (Yusdiana \& Satyawisudarini, 2018).

Analisis optimasi dapat diartikan sebagai suatu proses penguraian durasi proyek untuk mendapatkan percepatan durasi yang paling baik (optimal) dengan menggunakan berbagai alternatif. Proses memperpendek waktu kegiatan dalam jaringan kerja dengan mengurangi waktu pada jalur kritis sehingga waktu penyelesaian total dapat dikurangi yang disebut sebagai crashing proyek (Muhammad, 2015).

Proyek pada umumnya memiliki batas waktu (deadline) artinya proyek harus diselesaikan sebelum atau tepat pada waktu yang telah ditentukan (Taurusyanti \& Lesmana, 2015). Proyek konstruksi dapat diartikan sebagai suatu kegiatan sementara yang bertujuan untuk membangun sarana maupun prasarana yang berlangsung dalam jangka waktu terbatas dengan alokasi sumber dana tertentu dan dimaksudkan untuk mencapai tugas yang sasarannya telah digariskan secara jelas (Setiawati et al., 2017).

Perencanaan pembangunan proyek tentunya memerlukan analisis yang tepat dan sesuai dengan kebutuhan yang diinginkan. Kegiatan ini sangat dibutuhkan karena untuk mengukur berapa biaya yang akan dikeluarkan dan berapa kemampuan biaya untuk membangun proyek tersebut (Desyllia et al., 2011). Selain perencanaan pembangunan yang tepat tentunya juga membutuhkan perencanaan penjadwalan proyek yang baik (Karina Tika, 2015).

Penjadwalan sendiri harus disusun secara sistematis agar tujuan proyek bisa tercapai secara optimal. Proses perencanaan penjadwalan yang perlu dipahami adalah faktor-faktor yang melatarbelakangi pembuatan jadwal proyek (Karina Tika, 2015). Penjadwalan secara umum dapat diartikan sebagai penerjemah suatu rencana kegiatan proyek kedalam suatu jadwal kerja yang menunjukan urutan pelaksanaan berbagai kegiatan serta waktu dimulai dan diakhirinya setiap kegiatan yang bersangkutan (Taurusyanti \& Lesmana, 2015).

Keterlambatan proyek konstruksi berarti bertambahnya waktu pelaksanaan penyelesaian proyek yang telah direncanakan (Desyllia et al., 2011). Keterlambatan menunjukkan bahwa sebuah proyek tidak dapat diselesaikan sesuai dengan jadwal yang telah direncanakan sejak awal di dalam kontrak. Jadwal inilah yang menjadi kunci apakah sebuah proyek tersebut layak dikatakan terlambat (delay) atau tidak (Sakinah et al., 2015). Hal ini juga, tentu terjadi pada pembangunan jalan tol yang saat ini sedang gencar dilakukan oleh pemerintah Indonesia.

Pada proses pembangunan jalan tol ada beberapa pekerjaan yang dilakukan. Berikut adalah durasi perencanaan pekerjaan pembangunan jalan tol yang dapat dilihat pada tabel 1 . 
Jurnal SEOI - Fakultas Teknik Universitas Sahid Jakarta

Vol 3 edisi 2 tahun 2021

Tabel 1. Daftar Perencanaan Pekerjaan

\begin{tabular}{|l|l|l|}
\hline No. & Pekerjaan & $\begin{array}{l}\text { Durasi } \\
\text { (hari) }\end{array}$ \\
\hline 1 & Pembersihan Lahan & 25 \\
\hline 2 & Pembangunan Direksi Kit dan Gudang & 15 \\
\hline 3 & Melengkapi K3 dan Papan Nama & 10 \\
\hline 4 & Pondasi & 87 \\
\hline 5 & Pilecap & 99 \\
\hline 6 & Kolom & 27 \\
\hline 7 & Pier Head & 108 \\
\hline 8 & Stressing Girder & 80 \\
\hline 9 & Diaphfragma & 35 \\
\hline 10 & Slab & 70 \\
\hline 11 & Pelapisan Permukaan & 42 \\
\hline 12 & Pelapisan Aspal & 35 \\
\hline 13 & Parapet & 25 \\
\hline 14 & Lain - Lain & 20 \\
\hline 15 & Finishing & 15 \\
\hline
\end{tabular}

Dari uraian perencanaan pekerjaan pada tabel 1, pekerjaan pembangunan jalan tol dan durasi perencanaan pembangunan, perusahaan memiliki tanggung jawab untuk menyelesaikan proyek secara tepat waktu. Pengoptimalan durasi pembangunan bertujuan untuk pencegahan keterlambatan proyek dan meminimalisasi biaya serta percepatan kegiatan proyek pembangunan (Khofiyah \& Angreni, 2020).

Ada beberapa metode telah dikembangkan untuk mengatasi hal ini, diantaranya metode network planning. Metode network planning merupakan salah satu tehnik yang dapat digunakan oleh seorang manajer untuk membantu memutuskan berbagai masalah, khususnya perencanaan, penjadwalan dan pengendalian proyek. Berbagai macam analisis jaringan kerja yang sangat luas pemakaiannya adalah metode jalur kritis CPM (Critical Path Method) dan metode teknik evaluasi dan review proyek PERT (Program evaluation and review technique) (Yusdiana \& Satyawisudarini, 2018).

Metode CPM (Critical Path Method) adalah suatu metode yang bertujuan untuk menganalisis waktu dan biaya proyek melalui percepatan pekerjaan. Sebuah algoritma baru yang menggabungkan evaluasi diferensial yang ditingkatkan dan metode jalur kritis (CPM) berdasarkan strategi solusi terpisah multivariabel, diajukan untuk mencari solusi optimal global secara lebih efisien (Chen et al., 2015).

Metode PERT (Program evaluation and review technique) bertujuan untuk mencari kemungkinan tercapainya waktu proyek yang telah direncanakan dalam time schedule (Amirudin, 2018). Teknik PERT adalah pendekatan tradisional yang terkenal untuk ahli manajemen proyek (Mouhoub et al., 2011).

\subsection{Identifikasi Masalah}

Berdasarkan uraian latar belakang yang telah dijelaskan maka identifikasi masalahnya adalah perusahaan harus merencanakan penjadwalan proyek yang tepat agar proyek selesai tepat waktu sesuai dengan jadwal yang telah ditetapkan sejak awal atau tidak terlambat.

\subsection{Tujuan Penelitian}

Agar dapat mengetahui jalur kritis pada proyek pembangunan jalan setelah menggunakan metode CPM (Critical Path Method) dan untuk mengetahui berapa waktu yang didapat setelah 
melakukan penelitian menggunakan metode CPM (Critical Path Method). Kemudian untuk mengetahui berapa peluang waktu yang didapat dengan menggunakan metode PERT (Program Evaluation and Review Technique).

\section{Metodologi Penelitian}

Metode penelitian yang digunakan yaitu metode kualitatif dan kuantitatif, dengan menggunakan teknik penelitian statistik observasi. Untuk mendukung hasil yang diharapkan, metode $C P M$ dan PERT digunakan sebagai alat bantu untuk mencapai efektivitas penyelesaian proyek pembangunan jalan Tol Becakayu Seksi 1BC pada PT Delta Global Struktur.

Dalam melakukan penelitian diperlukan data-data yang akan digunakan untuk menyelesaikan masalah yang diteliti beberapa metode yang digunakan dalam pengumpulan data antaralain sebagai berikut:

\subsection{Studi Pustaka}

Dalam studi pustaka, data yang diperoleh dengan melalui berbagai literatur yang berhubungan dengan penjadwalan proyek untuk mengetahui faktor-faktor keterlambatan proses pembangunan jalan.

\subsection{Studi Lapangan}

Melakukan kunjungan pada PT Delta Global Struktur untuk mengetahui proses penjadwalan dan menganalisa berbagai permasalahan yang ada mengenai penjadwalan proyek.

\subsection{Wawancara}

Melakukan sesi tanya jawab untuk memperoleh keterangan mengenai penjadwalan proyek. Narasumber wawancara PT Delta Global Struktur adalah koordinator enginnering. Wawancara ini diharapkan dapat mengumpulkan data tentang penjadwalan pengerjaan proyek.

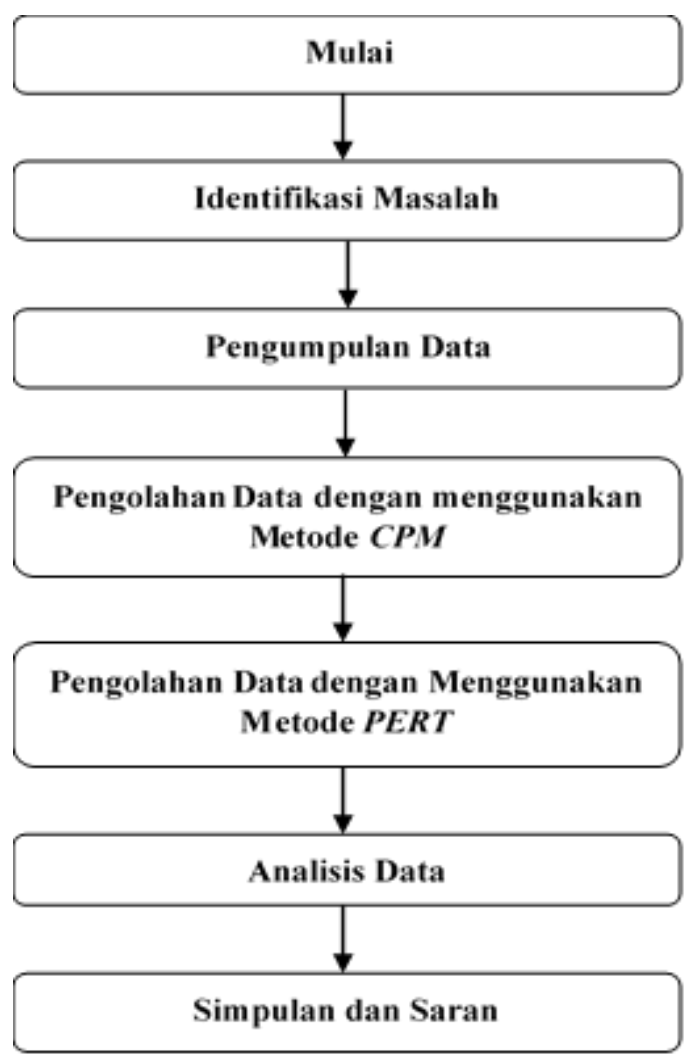

Gambar 1. Alur Penelitian 
Penelitian diawali dengan melakukan observasi pendahuluan agar diperoleh identifikasi masalah sebenarnya yang dihadapi pada proyek pembangunan jalan tol becakayu seksi 1BC yang didukung dan dibandingkan dengan teori dan penelitian terdahulu. Setelah itu melakukan pengumpulan data sesuai dengan data-data yang dibutuhkan berdasarkan tujuan penelitian yang telah ditetapkan.

Pengumpulan data dilakukan dengan observasi langsung ke lokasi proyek dan membandingan permasalahan-permasalahan yang terjadi dilapangan dengan proyek sebelumnya yang pernah dikerjakan. Setelah data yang diperlukan terkumpul penulis melakukan pengolahan data dengan menggunakan metode CPM (Critical Path Method) dan PERT (Project Evaluation and Review Technique). Metode CPM digunakan untuk mengetahui pekerjaan apa saja yang mengalami jalur kritis, kemudian melakukan pengolahan data dengan menggunakan metode PERT, metode ini bertujuan untuk mengetahui berapa persentasi keberhasilan proyek tersebut. Tahap selanjutnya melakukan analisis data, sehingga didapatkan hasil akhir kondisi proyek yang dikaitkan dengan rencana proyek yang telah ditetapkan. Tahap terakhir adalah menyampaikan simpulan dan saran terkait dengan hasil dari pengolahan data terhadap proyek pembangunan jalan Tol Becakayu Seksi 1BC.

\section{Hasil dan Pembahasan}

\subsection{Penyusunan Network Planning}

Menyusun network planning adalah cara awal untuk menguraikan kegiatan-kegiatan pada proyek pembangunan jalan tol dengan langkah-langkah sebagai berikut:

1. Memberikan kode pada setiap pekerjaan dengan tujuan untuk memudahkan penyusunan network planning.

2. Kemudian memasukan durasi pada setiap pekerjaan pembangunan jalan.

3. Selanjutnya menyusun pekerjaan proyek sesuai dengan urutan ketergantungan setiap pekerjaan dari awal proyek sampai dengan selesainya proyek Penyusunan sesuai langkahlangkah dapat dilihat seperti pada tabel 2.

Tabel 2 Network Planning

\begin{tabular}{|c|c|c|c|c|}
\hline No. & Kode & $\begin{array}{c}\text { Durasi } \\
\text { (hair) }\end{array}$ & Pendahulu & Lanjutan \\
\hline 1 & A & 25 & A & B,C \\
\hline 2 & B & 15 & B & D,E \\
\hline 3 & C & 10 & C & G \\
\hline 4 & D & 87 & D & F \\
\hline 5 & E & 99 & E & G \\
\hline 6 & F & 27 & F & H,I \\
\hline 7 & G & 108 & G & K \\
\hline 8 & H & 80 & H & J \\
\hline 9 & I & 35 & I & K \\
\hline 10 & J & 70 & J & L \\
\hline 11 & K & 42 & K & M \\
\hline 12 & L & 35 & L & N \\
\hline 13 & M & 25 & M & N \\
\hline 14 & N & 20 & N & O \\
\hline 15 & O & 15 & O & - \\
\hline
\end{tabular}


Kemudian hubungan antar kegiatan dibuat gambar diagram jaringan yang berfungsi untuk memudahkan kita dalam membaca pekerjaan awal dan pekerjaan selanjutnya. Gambar diagram jaringan dapat dilihat seperti pada gambar 2.

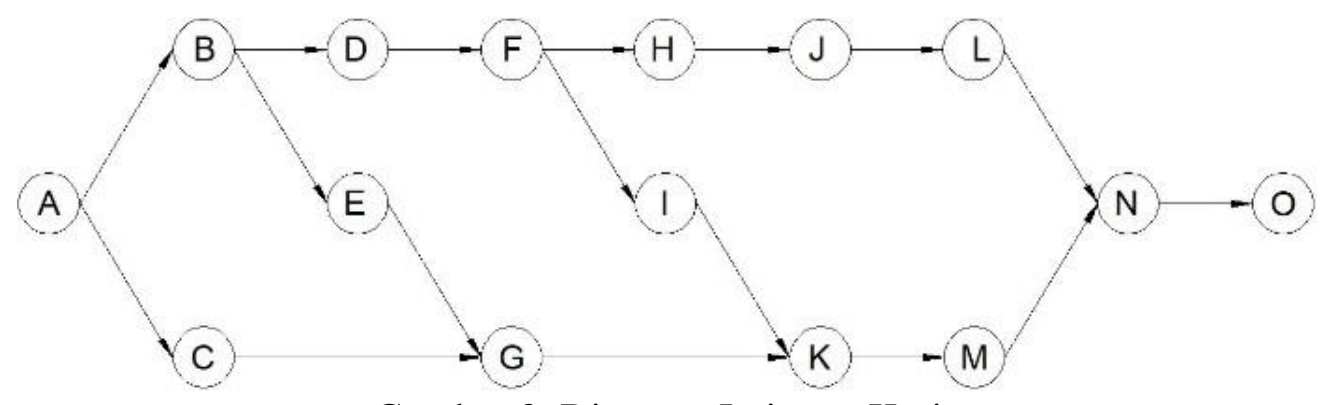

Gambar 2. Diagram Jaringan Kerja

\subsection{Metode CPM (Critical Path Method)}

Perhitungan Maju (Forward Pass) dimulai dari start (initial event) menuju finish (terminal event) untuk menghitung waktu penyelesaian tercepat suatu kegiatan $(E F)$, waktu tercepat terjadinya kegiatan $(E S)$ dan saat paling cepat dimulainya suatu peristiwa $(E)$. Aturan hitungan maju (Forward Pass) yaitu:

1. Kecuali pekerjaan awal maka suatu pekerjaan baru dapat dimulai bila pekerjaan yang mendahuluinya (predecessor) telah selesai

2. Waktu selesai paling awal suatu pekerjaan sama dengan waktu mulai paling awal, ditambah dengan kurun waktu pekerjaan yang mendahuluinya. $E F(\mathrm{i}-\mathrm{j})=E S(\mathrm{i}-\mathrm{j})+\mathrm{t}(\mathrm{i}-\mathrm{j})$.

3. Bila suatu kegiatan memiliki dua atau lebih kegiatan-kegiatan terdahulu yang menggabung maka waktu mulai paling awal (ES) kegiatan tersebut adalah sama dengan waktu selesai paling awal $(E F)$ yang terbesar dari kegiatan terdahulu.

Tabel 3. Perhitungan Maju (Forward Pass)

\begin{tabular}{|c|c|c|c|c|c|}
\hline $\begin{array}{c}\text { No. } \\
\text { Kegiatan }\end{array}$ & Kode & Early Start & $\begin{array}{c}\text { Durasi } \\
\text { (hari) }\end{array}$ & Early Finish & \multirow{2}{*}{ KET } \\
\hline 2 & A & 0 & 25 & 25 & \\
\hline 3 & B & 25 & 15 & 40 & \\
\hline 4 & D & 40 & 87 & 127 & \\
\hline 5 & F & 127 & 27 & 154 & \\
\hline \multirow{2}{*}{6} & C & 25 & 10 & 35 & \multirow{2}{*}{ diambil yang terbesar } \\
\cline { 2 - 5 } & E & 40 & 99 & 139 & \\
\hline 7 & H & 154 & 80 & 234 & \\
\hline 8 & J & 234 & 70 & 304 & \\
\hline \multirow{2}{*}{9} & G & 139 & 108 & 247 & \multirow{2}{*}{ diambil yang terbesar } \\
\cline { 2 - 5 } & I & 154 & 35 & 189 & \\
\hline 10 & K & 247 & 42 & 289 & \multirow{2}{*}{ diambil yang terbesar } \\
\hline \multirow{2}{*}{11} & L & 304 & 35 & 339 & \\
\cline { 2 - 5 } & M & 289 & 25 & 314 & \\
\hline 12 & N & 339 & 20 & 359 & \\
\hline 13 & O & 359 & 15 & 374 & \\
\hline
\end{tabular}

Pada tabel 3 perhitungan maju $C P M$ terdapat ada beberapa pekerjaan yang pekerjaan pendahulunya sama, contohya seperti pekerjaan $G$ dimana pendahulu pekerjaan $G$ adalah pekerjaan $\mathrm{C}$ dan $\mathrm{E}$ maka untuk menghitung pekerjaan selanjutnya diambil waktu terbesar dari hasil penjumlahan waktu pekerjaan $\mathrm{C}$ dan $\mathrm{E}$.

Perhitungan Mundur (Backward Pass) dimulai dari finish menuju start agar dapat mengidentifikasi saat paling lambat terjadinya suatu kegiatan $(L F)$, waktu paling lambat 
terjadinya suatu kegiatan $(L S)$ dan saat paling lambat suatu peristiwa terjadi $(L)$. Aturan hitungan mundur (Backward Pass) yaitu:

3.2.1 Waktu mulai paling akhir suatu kegiatan sama dengan waktu selesai paling akhir dikurangi kurun waktu berlangsungnya kegiatan yang bersangkutan. $L S(\mathrm{i}-\mathrm{j})=L F(\mathrm{i}$ $-\mathrm{j})-\mathrm{t}$

3.2.2 Apabila suatu kegiatan terpecah menjadi 2 kegiatan atau lebih maka waktu paling akhir $(L F)$ kegiatan tersebut sama dengan waktu mulai paling akhir $(L S)$ kegiatan berikutnya yang terkecil.

Tabel 4. Perhitungan Mundur (Backward Pass)

\begin{tabular}{|c|c|c|c|c|c|}
\hline \begin{tabular}{c|c} 
No. \\
Kegiatan
\end{tabular} & Kode & Late Finish & $\begin{array}{c}\text { Durasi } \\
\text { (hari) }\end{array}$ & Late Start & KET \\
\hline 12 & $\mathrm{O}$ & 374 & 15 & 359 & \\
\hline 11 & $\mathrm{~N}$ & 359 & 20 & 339 & \\
\hline 10 & $\mathrm{M}$ & 339 & 25 & 314 & \\
\hline 9 & $\mathrm{~K}$ & 314 & 42 & 272 & \\
\hline 8 & $\mathrm{~L}$ & 339 & 35 & 304 & \\
\hline 7 & $\mathrm{~J}$ & 304 & 70 & 234 & \\
\hline 6 & $\mathrm{G}$ & 272 & 108 & 164 & \\
\hline \multirow{2}{*}{5} & $\mathrm{H}$ & 234 & 80 & 154 & \multirow{2}{*}{ diambil yang terkecil } \\
\hline & $\mathrm{I}$ & 272 & 35 & 237 & \\
\hline 4 & $\mathrm{~F}$ & 154 & 27 & 127 & \\
\hline \multirow{2}{*}{3} & $\mathrm{D}$ & 127 & 87 & 40 & \multirow{2}{*}{ diambil yang terkecil } \\
\hline & $\mathrm{E}$ & 164 & 99 & 65 & \\
\hline \multirow{2}{*}{2} & $\mathrm{~B}$ & 40 & 15 & 25 & \multirow{2}{*}{ diambil yang terkecil } \\
\hline & $\mathrm{C}$ & 164 & 10 & 154 & \\
\hline 1 & A & 25 & 25 & 0 & \\
\hline
\end{tabular}

Sama seperti perhitungan maju pada tabel 3, perhitungan mundur CPM juga terdapat pekerjaan pendahulunya yang sama tetapi untuk perhitungan mundur dihitung dari pekerjaan selesai menuju pekerjaan awal dan untuk setiap pekerjaan waktunya dikurang dengan waktu pekerjaan selanjutnya. Contohnya seperti pada pekerjaan $\mathrm{F}$ dimana pekerjaan sebelumnya adalah pekerjaan $\mathrm{H}$ dan I maka untuk menghitung pekerjaan selanjutnya diambil yang terkecil dari pengurangan waktu pekerjaan $\mathrm{H}$ dan $\mathrm{I}$.

Setelah menghitung waktu perhitungan maju (Forward Pass) dengan mengambil waktu terbesar dan waktu perhitungan mundur (Backward Pass) mengambil waktu terkecil kemudian digambarkan dalam bentuk diagram jaringan yang dapat dilihat seperti pada gambar 3 .

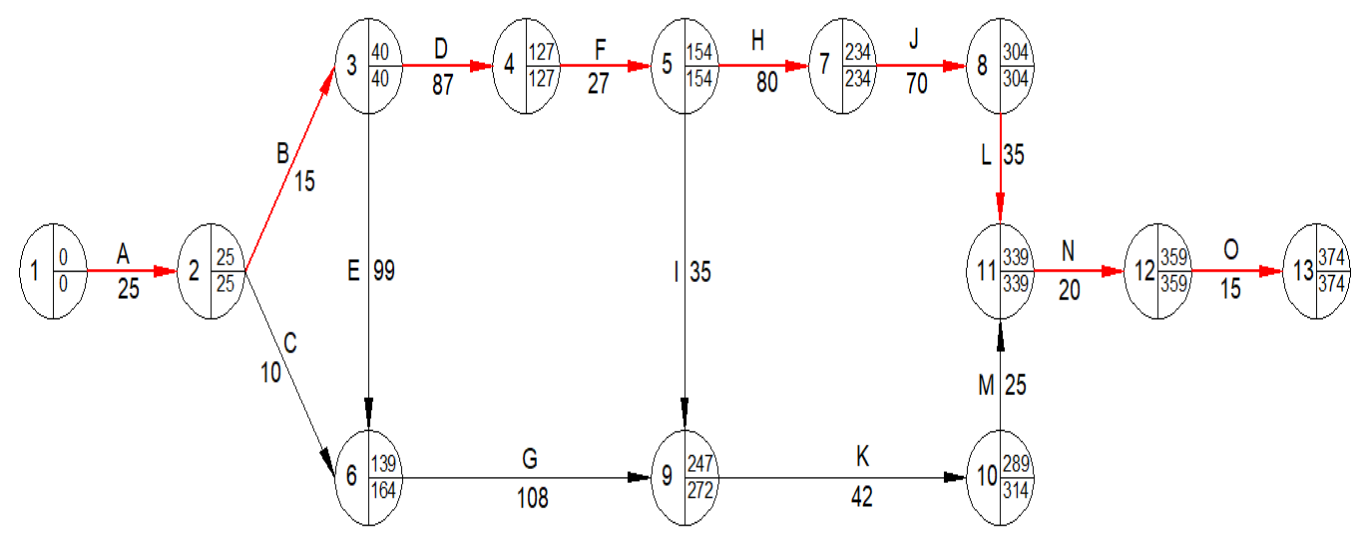

Gambar 3. Diagram Jaringan $C P M$ 
Pada gambar 3 diagram jaringan $C P M$, pelaksanaan proyek pembangunan jalan tol terdapat jalur kritis yaitu kegiatan pekerjaan A, B, D, F, H, J, L, N, O (panah merah) dengan waktu penyelesaian proyek yaitu 374 hari.

\subsection{Metode PERT (Project Evaluation and Review Technique)}

Memperkirakan waktu pekerjaan dan membandingkan dari data-data pengalaman masa lalu (historical record) maka data demikian akan berguna untuk bahan pembanding adapun estimasi waktu optimis, realistis dan optimis dapat dilihat pada tabel 5.

Tabel 5. Estimasi Durasi Optimis, realistis dan Pesimis
\begin{tabular}{|c|c|c|c|c|}
\hline No. & Kode & $\begin{array}{c}\text { Durasi } \\
\text { Optimis }(\boldsymbol{a})\end{array}$ & $\begin{array}{c}\text { Durasi } \\
\text { Realistis }(\boldsymbol{m})\end{array}$ & $\begin{array}{c}\text { Durasi } \\
\text { Pesimis }(\boldsymbol{b})\end{array}$ \\
\hline 1 & A & 20 & 25 & 30 \\
\hline 2 & B & 10 & 15 & 17 \\
\hline 3 & C & 10 & 10 & 12 \\
\hline 4 & D & 85 & 87 & 90 \\
\hline 5 & E & 90 & 99 & 103 \\
\hline 6 & F & 25 & 27 & 30 \\
\hline 7 & G & 100 & 108 & 110 \\
\hline 8 & H & 75 & 80 & 83 \\
\hline 9 & I & 30 & 35 & 37 \\
\hline 10 & J & 65 & 70 & 73 \\
\hline 11 & K & 40 & 42 & 45 \\
\hline 12 & L & 30 & 35 & 38 \\
\hline 13 & M & 20 & 25 & 28 \\
\hline 14 & N & 13 & 20 & 23 \\
\hline 15 & O & 10 & 15 & 18 \\
\hline
\end{tabular}

Setelah mengetahui estimasi durasi pekerjaan optimis, realistis dan pesimis maka dicari nilai te (durasi yang diharapkan) dengan menggunakan rumus sebagai berikut:

$$
\text { Rata }- \text { rata durasi }(t e)=\frac{a+4 m+b}{6}
$$

Dimana:

a : optimis time (hari)

$m \quad$ : realistis time (hari)

b : pesimistis time (hari)

Contoh perhitungan durasi pekerjaan (te) adalah sebagai berikut:

Pembersihan Lahan

a $=20$ hari

$m \quad=25$ hari

$b \quad=30$ hari

maka:

$$
\begin{aligned}
& (t e)=\frac{a+4 m+b}{6} \\
& (t e)=\frac{20+(4 \times 25)+30}{6} \\
& (t e)=25.00 \text { hari }
\end{aligned}
$$

Hasil dari perhitungan durasi pekerjaan yang diharapkan (te) selanjutnya dapat dilihat pada tabel 6 sebagai berikut: 
Jurnal SEOI - Fakultas Teknik Universitas Sahid Jakarta

Vol 3 edisi 2 tahun 2021

Tabel 6. Durasi Rata-Rata (te)

\begin{tabular}{|c|c|c|c|c|c|}
\hline No. & Kode & $\begin{array}{c}\text { Durasi } \\
\text { Optimis }(\boldsymbol{a})\end{array}$ & $\begin{array}{c}\text { Durasi } \\
\text { Realistis }(\boldsymbol{m})\end{array}$ & $\begin{array}{c}\text { Durasi } \\
\text { Pesimis }(\boldsymbol{b})\end{array}$ & $\begin{array}{c}\text { Durasi } \boldsymbol{t e}= \\
(\boldsymbol{a}+\mathbf{4} \boldsymbol{m}+\boldsymbol{b}) / \mathbf{6}\end{array}$ \\
\hline 1 & $\mathrm{~A}$ & 20 & 25 & 30 & 25.00 \\
\hline 2 & $\mathrm{~B}$ & 10 & 15 & 17 & 14.50 \\
\hline 3 & $\mathrm{C}$ & 10 & 10 & 12 & 10.33 \\
\hline 4 & $\mathrm{D}$ & 85 & 87 & 90 & 87.17 \\
\hline 5 & $\mathrm{E}$ & 90 & 99 & 103 & 98.17 \\
\hline 6 & $\mathrm{~F}$ & 25 & 27 & 30 & 27.17 \\
\hline 7 & $\mathrm{G}$ & 100 & 108 & 110 & 107.00 \\
\hline 8 & $\mathrm{H}$ & 75 & 80 & 83 & 79.67 \\
\hline 9 & $\mathrm{I}$ & 30 & 35 & 37 & 34.50 \\
\hline 10 & $\mathrm{~J}$ & 65 & 70 & 73 & 69.67 \\
\hline 11 & $\mathrm{~K}$ & 40 & 42 & 45 & 42.17 \\
\hline 12 & $\mathrm{~L}$ & 30 & 35 & 38 & 34.67 \\
\hline 13 & $\mathrm{M}$ & 20 & 25 & 28 & 24.67 \\
\hline 14 & $\mathrm{~N}$ & 13 & 20 & 23 & 19.33 \\
\hline 15 & $\mathrm{O}$ & 10 & 15 & 18 & 14.67 \\
\hline \multicolumn{2}{|c|}{ Total } & 623 & 693 & 737 & 688.67 \\
\hline
\end{tabular}

Dengan menggunakan nilai te (durasi yang diharapkan), dibuatlah sebuah diagram jaringan. Langkah membuat diagram jaringan PERT. Berikut merupakan hasil perhitungan maju (forward pass) pada tabel 7 dan perhitungan mundur (backward pass) pada tabel 8.

Tabel 7. Perhitungan Maju (te)

\begin{tabular}{|c|c|c|c|c|c|}
\hline $\begin{array}{c}\text { No. } \\
\text { Kegiata }\end{array}$ & Kode & Early Start & $\begin{array}{c}\text { Durasi } \\
\text { (hari) }\end{array}$ & Early Finish & KET \\
\hline 2 & $\mathrm{~A}$ & 0.00 & 25.00 & 25.00 & \\
\hline 3 & $\mathrm{~B}$ & 25.00 & 14.50 & 39.50 & \\
\hline 4 & $\mathrm{D}$ & 39.50 & 87.17 & 126.67 & \\
\hline 5 & $\mathrm{~F}$ & 126.67 & 27.17 & 153.84 & \\
\hline \multirow{2}{*}{6} & $\mathrm{C}$ & 25.00 & 10.33 & 35.33 & \multirow{2}{*}{ diambil yang terbesar } \\
\cline { 2 - 6 } & $\mathrm{E}$ & 39.20 & 98.17 & 137.37 & \\
\hline 7 & $\mathrm{H}$ & 153.84 & 79.67 & 233.51 & \\
\hline 8 & $\mathrm{~J}$ & 233.51 & 69.67 & 303.18 & \\
\hline \multirow{2}{*}{9} & $\mathrm{G}$ & 137.37 & 107.00 & 244.37 & \multirow{2}{*}{ diambil yang terbesar } \\
\cline { 2 - 6 } & $\mathrm{I}$ & 153.84 & 34.50 & 188.34 & \\
\hline 10 & $\mathrm{~K}$ & 244.37 & 42.17 & 286.54 & \\
\hline \multirow{2}{*}{11} & $\mathrm{~L}$ & 303.18 & 34.67 & 337.85 & \multirow{2}{*}{ diambil yang terbesar } \\
\cline { 2 - 5 } & $\mathrm{M}$ & 286.54 & 24.67 & 311.21 & \\
\hline 12 & $\mathrm{~N}$ & 337.85 & 19.33 & 357.18 & \\
\hline 13 & $\mathrm{O}$ & 357.18 & 14.67 & 371.85 & \\
\hline
\end{tabular}


Jurnal SEOI - Fakultas Teknik Universitas Sahid Jakarta

Vol 3 edisi 2 tahun 2021

Tabel 8. Perhitungan Mundur (te)

\begin{tabular}{|c|c|c|c|c|c|}
\hline $\begin{array}{c}\text { No. } \\
\text { Kegiata }\end{array}$ & Kode & Late Finish & $\begin{array}{c}\text { Durasi } \\
\text { (hari) }\end{array}$ & Late Start & KET \\
\hline 12 & O & 371.85 & 14.67 & 357.18 & \\
\hline 11 & N & 357.18 & 19.33 & 337.85 & \\
\hline 10 & M & 337.85 & 24.67 & 313.18 & \\
\hline 9 & K & 313.18 & 42.17 & 271.01 & \\
\hline 8 & L & 337.85 & 34.67 & 303.18 & \\
\hline 7 & J & 303.18 & 69.67 & 233.51 & \\
\hline 6 & G & 270.01 & 107.00 & 163.01 & \\
\hline \multirow{2}{*}{5} & H & 233.51 & 79.67 & 153.84 & \multirow{2}{*}{ diambil yang terkecil } \\
\cline { 2 - 5 } & I & 270.01 & 34.50 & 235.51 & \\
\hline 4 & F & 153.84 & 27.17 & 126.67 & \\
\hline \multirow{2}{*}{3} & D & 126.67 & 87.17 & 39.50 & \multirow{2}{*}{ diambil yang terkecil } \\
\cline { 2 - 5 } & E & 164.01 & 98.17 & 65.84 & \multirow{2}{*}{ diambil yang terkecil } \\
\hline \multirow{2}{*}{2} & B & 39.50 & 14.50 & 25.00 & \\
\cline { 2 - 5 } & C & 164.01 & 10.33 & 153.68 & \multirow{2}{*}{} \\
\hline 1 & A & 25.00 & 25.00 & 0.00 & \\
\hline
\end{tabular}

Sama seperti metode $C P M$ langkah perhitungan maju dan perhitungan mudur pada waktu te juga terdapat beberapa pekerjaan yang pendahulunya sama maka pada perhitungan maju diambil waktu yang terbesar dan pada perhitungan mundur diambil waktu yang terkecil kemudian digambar diagram jaringan seperti pada gambar 9 berikut ini.

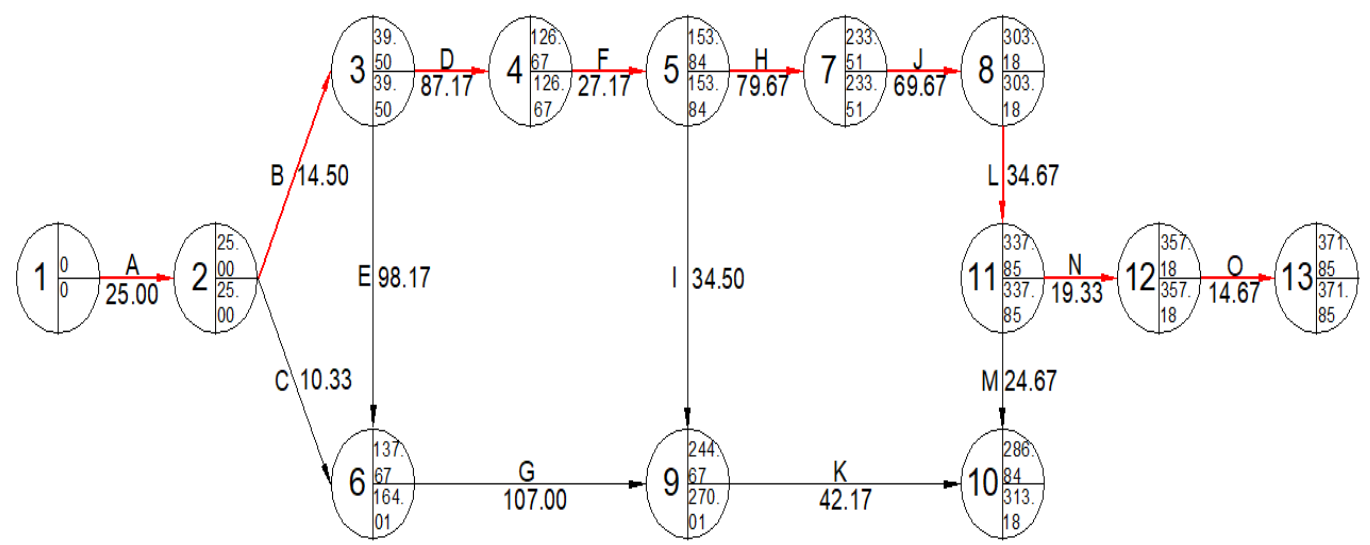

Gambar 4 Diagram Jaringan PERT

Pada gambar 4, diagram jaringan PERT, pelaksanaan proyek pembangunan jalan tol terdapat jalur kritis yang sama dengan metode $C P M$ yaitu A, B, D, F, H, J, L, N, O (panah merah) dengan waktu penyelesaian proyek yaitu 371 hari. Setelah menghitung waktu rata-rata pekerjaan kemudian melakukan perhitungan standar deviasi dan varians sebagai berikut:

Standar deviasi (se)

Rumus standar deviasi

$$
(s e)=\frac{b-a}{6}
$$

Dimana:

$\begin{array}{ll}a & \text { : optimis time (hari) } \\ b & \text { : pesimis time (hari) } \\ 6 & \text { : Standar deviasi }\end{array}$


Jurnal SEOI - Fakultas Teknik Universitas Sahid Jakarta

Vol 3 edisi 2 tahun 2021

Contoh perhitungan standar deviasi (se) adalah sebagai berikut:

Pembersihan Lahan

$a \quad=20$ hari

$b \quad=30$ hari

6

maka

$$
\begin{aligned}
& (s e)=\frac{b-a}{6} \\
& (s e)=\frac{30-20}{6} \\
& (s e)=1.67 \text { hari }
\end{aligned}
$$

Standar varians (ve)

Rumus standar varians:

$$
(v e)=\left\{\frac{b-a}{6}\right\}^{2}
$$

Dimana:

$$
\begin{array}{cl}
a & : \text { optimis time (hari) } \\
b & : \text { pesimis time (hari) } \\
6 & : \text { Standar deviasi }
\end{array}
$$

Contoh perhitungan standar varians (ve) adalah sebagai berikut:

Pembersihan Lahan

$$
\begin{array}{ll}
a & =20 \text { hari } \\
b & =30 \text { hari } \\
6 & \\
\text { maka } &
\end{array}
$$

$$
\begin{aligned}
& (v e)=\left\{\frac{b-a}{6}\right\}^{2} \\
& (v e)=\left\{\frac{30-20}{6}\right\}^{2} \\
& (v e)=1.67^{2} \\
& (v e)=3.33 \text { hari }
\end{aligned}
$$

Dengan menggunakan rumus deviasi ( $s e$ ) dan varians (ve) di atas didapatkan hasil seperti pada tabel 3.8.

Tabel 9. Deviasi dan Varians 
Jurnal SEOI - Fakultas Teknik Universitas Sahid Jakarta

Vol 3 edisi 2 tahun 2021

\begin{tabular}{|c|c|c|c|c|c|c|}
\hline No. & Kode & $\begin{array}{c}\text { Durasi } \\
\text { Pesimis }(\boldsymbol{a})\end{array}$ & $\begin{array}{c}\text { Durasi } \\
\text { Realistis }(\boldsymbol{m})\end{array}$ & $\begin{array}{c}\text { Durasi } \\
\text { Pesimis }(\boldsymbol{b})\end{array}$ & $\begin{array}{c}\text { Deviasi } \\
\mathbf{s = 1 / 6 ( b - a )}\end{array}$ & $\begin{array}{c}\text { Varians } \\
\mathbf{V =} \mathbf{S}^{\mathbf{2}}\end{array}$ \\
\hline 1 & $\mathrm{~A}$ & 20 & 25 & 30 & 1.67 & 3.33 \\
\hline 2 & $\mathrm{~B}$ & 10 & 15 & 17 & 1.17 & 2.33 \\
\hline 3 & $\mathrm{C}$ & 10 & 10 & 12 & 0.33 & 0.67 \\
\hline 4 & $\mathrm{D}$ & 85 & 87 & 90 & 0.83 & 1.67 \\
\hline 5 & $\mathrm{E}$ & 90 & 99 & 103 & 2.17 & 4.33 \\
\hline 6 & $\mathrm{~F}$ & 25 & 27 & 30 & 0.83 & 1.67 \\
\hline 7 & $\mathrm{G}$ & 100 & 108 & 110 & 1.67 & 3.33 \\
\hline 8 & $\mathrm{H}$ & 75 & 80 & 83 & 1.33 & 2.67 \\
\hline 9 & $\mathrm{I}$ & 30 & 35 & 37 & 1.17 & 2.33 \\
\hline 10 & $\mathrm{~J}$ & 65 & 70 & 73 & 1.33 & 2.67 \\
\hline 11 & $\mathrm{~K}$ & 40 & 42 & 45 & 0.83 & 1.67 \\
\hline 12 & $\mathrm{~L}$ & 30 & 35 & 38 & 1.33 & 2.67 \\
\hline 13 & $\mathrm{M}$ & 20 & 25 & 28 & 1.33 & 2.67 \\
\hline 14 & $\mathrm{~N}$ & 13 & 20 & 23 & 1.67 & 3.33 \\
\hline 15 & $\mathrm{O}$ & 10 & 15 & 18 & 1.33 & 2.67 \\
\hline
\end{tabular}

Untuk mengetahi peluang probabilitas pada proyek pembangunan jalan tol dengan menggunakan rumus seperti dibawah

Varian proyek $\quad=\Sigma$ (varians kegiatan pada kegiatan kritis)

$$
\begin{aligned}
& =\text { varians } \mathrm{A}+\text { varians } \mathrm{B}+\text { varians } \mathrm{D}+\text { varians } \mathrm{F}+\text { varians } \mathrm{H}+\text { varians } \mathrm{J} \\
& + \text { varians } \mathrm{L}+\text { varians } \mathrm{N}+\text { varians } \mathrm{O} \\
& =3.33+2.33+1.67+1.67+2.67+2.67+2.67+3.33+2.67 \\
& =23.00
\end{aligned}
$$

Standar varians proyek (ve)

$$
\begin{array}{ll}
= & \quad \sqrt{\text { Varians proyek }} \\
= & \sqrt{23.00} \\
= & 4.80
\end{array}
$$

Kemudian perusahaan ingin mengetahui berapa peluang untuk menyelesaikan dengan durasi realistis $(m) 693$ hari maka.

Nilai deviasi normal $(\mathrm{z})$ :

$$
\begin{aligned}
& =[m-t e] / \mathrm{s} \\
& =(693-689) / 4.80 \\
& =0,83
\end{aligned}
$$

Tabel 10. Tabel Distribusi z Normal 
Jurnal SEOI - Fakultas Teknik Universitas Sahid Jakarta

Vol 3 edisi 2 tahun 2021

\begin{tabular}{|lllll|l|ll}
\hline $\boldsymbol{Z}$ & $\mathbf{0 . 0 0}$ & $\mathbf{0 . 0 1}$ & $\mathbf{0 . 0 2}$ & $\mathbf{0 . 0 3}$ & $\mathbf{0 . 0 4}$ & $\mathbf{0 . 0 5}$ \\
\hline 0.0 & 0.5000 & 0.5040 & 0.5080 & 0.5120 & 0.5160 & 0.5199 \\
0.1 & 0.5398 & 0.5438 & 0.5478 & 0.5517 & 0.5557 & 0.5596 \\
0.2 & 0.5793 & 0.5832 & 0.5871 & 0.5910 & 0.5948 & 0.5987 \\
0.3 & 0.6179 & 0.6217 & 0.6255 & 0.6293 & 0.6331 & 0.6368 \\
0.4 & 0.6554 & 0.6591 & 0.6628 & 0.6664 & 0.6700 & 0.6736 \\
0.5 & 0.6915 & 0.6950 & 0.6985 & 0.7019 & 0.7054 & 0.7088 \\
0.6 & 0.7257 & 0.7291 & 0.7324 & 0.7357 & 0.7389 & 0.7422 \\
0.7 & 0.7580 & 0.7612 & 0.7642 & 0.7673 & 0.7704 & 0.7734 \\
\hline 0.8 & 0.7881 & 0.7910 & 0.7939 & 0.7967 & 0.7995 & 0.8023 \\
\hline 0.9 & 0.8159 & 0.8186 & 0.8212 & 0.8238 & 0.8264 & 0.8289 \\
1.0 & 0.8413 & 0.8438 & 0.8461 & 0.8485 & 0.8508 & 0.8531 \\
1.1 & 0.8643 & 0.8665 & 0.8686 & 0.8708 & 0.8729 & 0.8749 \\
1.2 & 0.8849 & 0.8869 & 0.8888 & 0.8907 & 0.8925 & 0.8944 \\
1.3 & 0.9032 & 0.9049 & 0.9066 & 0.9082 & 0.9099 & 0.9115 \\
1.4 & 0.9192 & 0.9207 & 0.9222 & 0.9236 & 0.9251 & 0.9265 \\
1.5 & 0.9332 & 0.9345 & 0.9357 & 0.9370 & 0.9382 & 0.9394
\end{tabular}

Dengan hasil niali devisi normal sebesar 0.83 kemudian merujuk pada tabel distribusi z normal, perusahaan mendapat peluang 0.7967 yang artinya ada peluang sebesar $79.67 \%$ untuk perusahaan dapat menyelesaikan proyek pembangunan jalan Tol Becakayu Seksi 1BC.

\subsection{Pembahasan}

Dari hasil pengolahan data di atas pada metode CPM pembangunan jalan Tol Becakayu Seksi 1BC terdapat jalur kritis yaitu kegiatan pekerjaan:

$\mathrm{A}=$ Pekerjaan Pembebasan Lahan

$\mathrm{B}=$ Pekerjaan Pembangunan Direksi Kit dan Gudang

$\mathrm{D}=$ Pekerjaan Pondasi

$\mathrm{F}=$ Pekerjaan Kolom

$\mathrm{H}=$ Pekerjaan Stressing Girder

$\mathrm{J}=$ Pekerjaan Slab

$\mathrm{L}=$ Pekerjaan Pelapisan Aspal

$\mathrm{N}=$ Pekerjaan Lain-lain dan

$\mathrm{O}=$ Pekerjaan Finishing

Kegiatan pekerjaan yang mengalami jalur kritis memiliki waktu penyelesaian proyek yaitu 374 hari sedangkan pada metode PERT dengan jalur kritis yang sama seperti metode $C P M$ akan tetapi waktu penyelesaiannya berbeda dimana pada metode PERT jalur kritisnya yaitu:

$\mathrm{A}=$ Pekerjaan Pembebasan Lahan

$\mathrm{B}=$ Pekerjaan Pembangunan Direksi Kit dan Gudang

$\mathrm{D}=$ Pekerjaan Pondasi

$\mathrm{F}=$ Pekerjaan Kolom

$\mathrm{H}=$ Pekerjaan Stressing Girder

$\mathrm{J}=$ Pekerjaan Slab

$\mathrm{L}=$ Pekerjaan Pelapisan Aspal

$\mathrm{N}=$ Pekerjaan Lain-lain dan

$\mathrm{O}=$ Pekerjaan Finishing

Dimana durasi waktu penyelesaian proyek pada metode PERT 371.85 kemudian dibulatkan menjadi 372 hari. Jalur kritis biasanya memakan durasi pengerjaan terpanjang dalam suatu proyek. Jalur kritis adalah jalur yang tidak memiliki tengang waktu antara selesainya pekerjaan dengan pekerjaan selanjutnya. Artinya pekerjaan yang terdapat jalur kritis 
Jurnal SEOI - Fakultas Teknik Universitas Sahid Jakarta

Vol 3 edisi 2 tahun 2021

harus dikerjakan tepat waktu agar tidak menyebabkan bertambahnya durasi penyelesaian proyek.

Meskipun metode $C P M$ dan PERT berbeda pada beberapa hal dalam terminologi dan pada konstruksi jaringan tetapi tujuan mereka sama. Analisis yang digunakan pada kedua teknik ini sangat mirip. Perbedaan utamanya adalah bahwa PERT menggunakan tiga perkiraan waktu untuk tiap kegiatan. Perkiraan waktu ini digunakan untuk menghitung nilai yang diharapkan dengan probabilitas perbandingan dari tabel distribusi nilai $\mathrm{Z}$ didapatkan hasil 79,67 \%. Dedangkan meotde $C P M$ membuat asumsi bahwa waktu kegiatan diketahui pasti, hingga hanya diperlukan satu faktor waktu untuk tiap kegiatan

\section{Kesimpulan}

Berdasarkan hasil dari pengelolahan data terhadap proyek pembangunan jalan Tol Becakayu Seksi 1BC maka dapat disimpulkan sebagai berikut:

1. Pada proyek pembangunan jalan tol dengan menggunakan metode $C P M$ terdapat jalur kritis dimana kegiatan pekerjaan tersebut adalah Pekerjaan Pembebasan Lahan, Pekerjaan Pembangunan Direksi Kit dan Gudang, Pekerjaan Pondasi, Pekerjaan Kolom, Pekerjaan Stressing Girder, Pekerjaan Slab, Pekerjaan Pelapisan Aspal, Pekerjaan Lain-lain dan Pekerjaan Finishing.

2. Durasi kegiatan pekerjaan yang didapat dari hasil pengolahan data dengan menggunakan metode $C P M$ sebesar 374 hari dimana durasi tersebut harus diselesaikan secara tepat waktu agar tidak berdampak terhadap kegiatan pekerjaan lainya.

3. Setelah melakukan pengolahan data menggunakan metode PERT peluang yang didapatkan perusahaan sebesar $79.67 \%$ untuk perusahaan dapat menyelesaikan proyek pembangunan jalan Tol Becakayu Seksi 1BC.

4. Agar tidak terjadi penundaan dalam melaksanakan proyek maka kegiatan pekerjaan di dalam jalur kritis perlu diawasi dan kontrol dengan ketat agar tidak terlambat dan juga mengakibatkan kegiatan pekerjaan yang tidak di dalam jalur kritis terganggu. Pembangunan suatu proyek konstruksi, sebaiknya metode perencanaan dan manajemen pelaksanaan proyek dapat diperhatikan lebih karena peranan metode perencanaan dan manajemen pelaksanaan sangat penting terhadap proyek kontruksi mulai dari awal sampai akhir pelaksanaan proyek tersebut.

\section{Daftar Pustaka}

Amirudin. (2018). Optimasi pelaksanaan proyek konstruksi dengan metode pert dan cpm.

Chen, K., Si, J., Zhou, F., Zhang, R., Shao, H., \& Zhao, H. (2015). Optimization of air quantity regulation in mine ventilation networks using the improved differential evolution algorithm and critical path method. International Journal of Mining Science and Technology, 25(1), 79-84. https://doi.org/10.1016/j.ijmst.2014.11.001

Desyllia, Chendra, F., \& Chandra, H. P. (2011). Model Faktor-Faktor Penyebab dan Dampak Keterlambatan Proyek Kontruksi di Surabaya. Program Studi Teknik Sipil, 402-402. https://doi.org/10.1007/978-0-387-79061-9_6201

Karina Tika, F. R. (2015). Estimasi Biaya Dan Penjadwalan Proyek Konstruksi. 2015, 172174.

Khofiyah, O. L., \& Angreni, I. A. A. (2020). Pengaruh Pembebasan Tanah terhadap Keterlambatan Proyek Pembangunan Jalan Tol Studi Kasus: Jalan Tol Cinere-Jagorawi

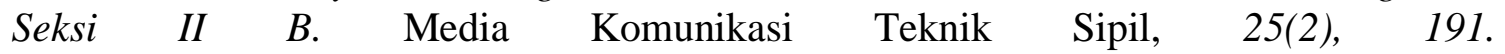
https://doi.org/10.14710/mkts.v25i2.20048

Mouhoub, N. E., Benhocine, A., \& Belouadah, H. (2011). A new method for constructing a minimal PERT network. Applied Mathematical Modelling, 35(9), 4575-4588. https://doi.org/10.1016/j.apm.2011.03.031 
Jurnal SEOI - Fakultas Teknik Universitas Sahid Jakarta

Vol 3 edisi 2 tahun 2021

Muhammad, A. H. (2015). Opimasi Pelaksanaan Proyek Kontruksi dengan Metode PERT dan CPM. 1(1).

Sakinah, B. F., Hasyim, M. H., \& Unas, S. El. (2015). Analisis Penyebab Keterlambatan pada Pekerjaan Kontruksi Jalan Kabupaten Lombok Tengan Dengan Metode Analisa Faktor. Jurusan Teknik Sipil.

Setiawati, S., Syahrizal, \& Rezky Ariessa Dewi. (2017). Penerapan Metode CPM Dan PERT Pada Penjadwalan Proyek Konstruksi (Studi Kasus: Rehabilitasi / Perbaikan Dan Peningkatan Infrastruktur Irigasi Daerah Lintas Kabupaten/Kota D.I Pekan Dolok). Jurnal $\begin{array}{llll}\text { Teknik Sipil USU, 6(1), 1-14. } & \text {. }\end{array}$ https://jurnal.usu.ac.id/index.php/jts/article/viewFile/16596/7011

Taurusyanti, D., \& Lesmana, M. F. (2015). Optimalisasi Penjadwalan Proyek Jembatan Girder Guna Mencapai Efektifitas Penyelesaian Dengan Metode Pert Dan Cpm Pada Pt Buana Masa Metalindo. JIMFE (Jurnal Ilmiah Manajemen Fakultas Ekonomi), 1(1), 3236. https://doi.org/10.34203/jimfe.v1i1.451

Yusdiana, E. D., \& Satyawisudarini, I. (2018). Penerapan Metode PERT Dan CPM Dalam Pelaksanaan Proyek Pembangunan Jalan Paving Untuk Mencapai Efektivitas Waktu Penyelesaian Proyek. Jurnal Manajemen Dan Bisnis, 2(3), 20-30. https://www.uam.es/gruposinv/meva/publicaciones

jesus/capitulos_espanyol_jesus/2005_motivacion para el aprendizaje Perspectiva alumnos.pdf\%0Ahttps://www.researchgate.net/profile/Juan_Aparicio7/publication/2535 71379_Los_estudios_sobre_el_cambio_conceptual_ 